\title{
Development and validation of an ultra-high performance liquid chromatography photodiode array method for the quantification of donepezil in human plasma and its application
}

\author{
Rasda Boonprasert*, Tippanate Keawvijit, Supawadee Pakdeenukoolkijja \\ Clinical Toxicology Laboratory, Siriraj Poison Control Center, Faculty of Medicine Siriraj Hospital, Mahidol University, Bangkok, Thailand
}

\begin{abstract}
An ultra-high performance liquid chromatography-photodiode array detection (UHPLC-PDA) method was developed and validated for determination of the concentration of donepezil in patient's plasma. Plasma spiked with diphenhydramine as an internal standard was used for the solid phase extraction. The eluent solution was diluted with $0.05 \%$ trifluoroacetic acid and injected into an UHPLC system. Chromatographic separation was performed on a reverse phase column $(1.8 \mu \mathrm{m}, 100 \mathrm{~mm} \times 2.1 \mathrm{~mm}$ I.D. $)$ and using acetonitrile with $0.05 \%$ trifluoroacetic acid in milli-Q water as the mobile phase. The gradient program for the mobile phase involved a flow rate of $0.45 \mathrm{~mL} / \mathrm{min}$ and $3 \mathrm{~min}$ total run time. The photodiode array (PDA) detector was chosen to operate at $230 \mathrm{~nm}$. The retention times were 1.70 and $2.11 \mathrm{~min}$ for donepezil and diphenhydramine, respectively. The method was developed and fully validated according to United Stated Food and Drug Administration (USFDA) guidance. The linearity of the method revealed a coefficient of determination or square of $r$ greater than 0.998 in the concentration range 10-250 $\mathrm{ng} / \mathrm{mL}$. Extraction recoveries ranged from 84.6-85.6\% with good repeatability. A simple, rapid, and reproducible UHPLC/PDA method for quantifying the concentration of donepezil in patient's plasma was thus developed and completely validated. This method was successfully utilized to measure the plasma concentration of 105 Thai patients with Alzheimer's disease and vascular dementia.
\end{abstract}

\section{Keywords:}

Donepezil, UHPLC-PDA, Therapeutic drug monitoring

\section{INTRODUCTION}

Donepezil (DP) is an acetylcholinesterase inhibitor (AchE-I) which can reduce the degradation of acetylcholine and has been authorized for the treatment of mild to moderate Alzheimer disorder $(\mathrm{AD})^{1}$. It has been shown that there is a statistically significant correlation between increased plasma concentrations of donepezil in plasma and acetylcholinesterase inhibition; whereby at a donepezil plasma concentration of $15.6 \mathrm{ng} / \mathrm{ml}, 50 \%$ of acetylcholinesterase activity was inhibited, while above 50 $\mathrm{ng} / \mathrm{ml}, 80-90 \%$ of inhibition was achieved ${ }^{2}$. A higher oral dosage was thus recommended in that study for an improved therapeutic response toward the mentioned outcomes. However, therapeutic response of donepezil is usually about $20-30 \%$. Inter-individual variability may additionally occur from genetic factors in particular polymorphisms of gene, which is a necessary function in many pharmacokinetic systems ${ }^{3}$. Therefore, therapeutic drug monitoring (TDM) could also be a beneficial device to predict the medical results of donepezil in the treatment of Alzheimer's disease ${ }^{4-5}$.

Several studies have suggested the use of HPLC with UV for quantitation of donepezil in pharmacokinetic studies, pharmaceutical preparations and $\mathrm{TDM}^{6-8}$. However while the most common method have high sensitivity, their limitation include long chromatographic run times and the need for an additional extraction

\section{*Corresponding author:}

*Rasda Boonprasert Email: rasda.boo@mahidol.ac.th 
process. The highest sensitivity can be achieved by using liquid chromatography-tandem mass spectrometry (LCMS/MS $)^{9-13}$, but this is a difficult technique to apply. Consequently, there is a need for a high sensitivity, short chromatographic run time, simple technique to fulfill the requirements for the use in therapeutic drug monitoring. In this present study, a sensitive, selective and fast ultra high performance liquid chromatography photodiode array method (UHPLC-PDA) method was developed for determination of donepezil in patient's plasma. The method was validated in line with Guidance for Industry, Bio-analytical Methods Validation, U.S. Department of Health and Human Services, Food and Drug Administration, Center for Drug Evaluation and Research (USFDA CDER, 2018, BP) ${ }^{14}$. This method can be utilized for the determination of donepezil plasma concentration on TDM studies.

\section{MATERIALS AND METHODS}

\subsection{Instruments and analytical conditions}

An Acquity $^{\mathrm{TM}}$ Ultra Performance Liquid Chromatography (Waters Corporation, Milford, MA, USA) used to be the separation module. Chromatographic separation was performed on an ACQUITY UPLC $^{\circledR}$ BEH HSS T3 column $(1.8 \mu \mathrm{m}, 100 \mathrm{~mm} \times 2.1$ mm I.D.) (Waters Corporation, Milford, MA, USA). To obtain the appropriate result, the mobile phase was carried out with a flow rate of $0.45 \mathrm{~mL} / \mathrm{min}$ and a column temperature of $40^{\circ} \mathrm{C}$. The gradient program for the mobile phase was optimized using acetonitrile and $0.05 \%$ trifluoroacetic acid (TFA) in milli-Q water. An ACQUITY UPLC ${ }^{\circledR}$ Photodiode Array (PDA) Detector (Waters Corporation, Milford, MA, USA) was operated at wavelengths between $200-380 \mathrm{~nm}$ and quantitation was optimized on the requirement for high sensitivity and specificity. The auto-sampler was conditioned at $8^{\circ} \mathrm{C}$ and the injection volume was $10 \mu \mathrm{L}$. Empower 2 software program (Waters Corporation, Milford, MA, USA) was used for data management.

\subsection{Chemicals and reagents}

Donepezil hydrochloride and diphenhydramine (internal standard, IS) were purchased from SigmaAldrich Ltd. (Steinheim, Germany) and their chemical structure are presented in Figure 1. HPLC grade acetonitrile and methanol were purchased from Labscan Ltd. (Bangkok, Thailand). The water used for the experiments was made through milli- ${ }^{\circledR}$ water purification system (EMD Millipore, Billerica, MA, USA). All other chemicals used were of analytical grade. Drug-free human plasma was obtained from the Department of Transfusion Medicine, Faculty of Medicine Siriraj Hospital.

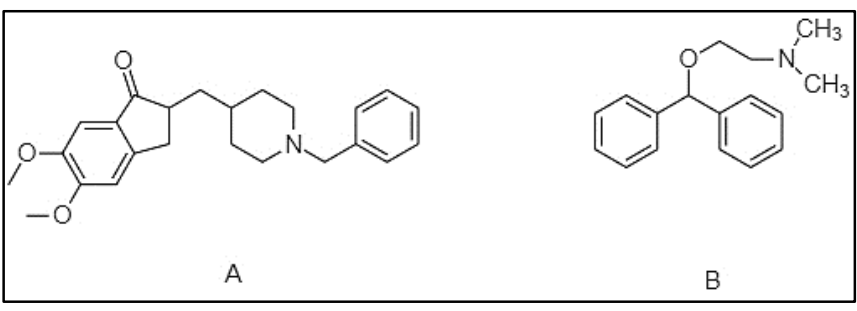

Figure 1. Chemical structures of donepezil (A) and diphenhydramine (B).

\subsection{Standard solution preparation and calibration curve}

The donepezil hydrochloride and diphenhydramine standard were accurately weighed. Primary standard stock solutions of each were prepared in dimethyl sulfoxide (DMSO) with a final concentration of $50,000 \mathrm{ng} / \mathrm{mL}$. Working standard solutions were prepared by diluting of the stock standard solutions with a mixture of methanol and water $(50: 50, \mathrm{v} / \mathrm{v})$ to a final concentration that varied between $500-12,500 \mathrm{ng} / \mathrm{mL}$ to be used as calibration standards (CSs). Six different concentrations of CS were organized by spiking the working standard solutions in drug-free human plasma to give the desired concentration; a 10, 50, 100, 150, 200 and $250 \mathrm{ng} / \mathrm{mL}$. Meanwhile, the quality control samples (QC) were prepared separately in the same way to create low, medium, and high concentration controls at 30,120 and $220 \mathrm{ng} / \mathrm{mL}$, respectively. The IS working standard solution was prepared by diluting the primary standard stock solutions with a combination of methanol and water $(50: 50, \mathrm{v} / \mathrm{v})$ to a final concentration of 200 $\mathrm{ng} / \mathrm{mL}$. All standard stock solutions, working solutions, and QC samples were stored at $-20^{\circ} \mathrm{C}$ untill use

\subsection{Sample preparation}

For solid phase extraction (SPE), OASIS HLB: Hydrophilic-Lipophilic-Balanced reversed- phase sorbent $30 \mathrm{mg} 1 \mathrm{~mL}$ (Waters Corporation, Milford, MA, USA) was used for sample preparation. SPE HLB cartridges were first conditioned with $1 \mathrm{~mL}$ of methanol and equilibrated with $1 \mathrm{~mL}$ of milli-Q water before use. Next, $20 \mu \mathrm{L}$ of IS $(200 \mathrm{ng} / \mathrm{mL})$ was added into $1.0 \mathrm{~mL}$ of the plasma samples in $2.0 \mathrm{~mL}$ micro-centrifuge tube, and $200 \mu \mathrm{L}$ orthophosphoric acid was then added and mixed immediately. Then, $1 \mathrm{~mL}$ aliquots of the plasma samples were aspirated into the wetted preconditioned SPE HLB cartridges. The plasma components were then washed in two steps with wash solvent, $1 \mathrm{~mL}$ ammonia solution in water $(2: 98, \mathrm{v} / \mathrm{v})$ and then $1 \mathrm{~mL}$ of ammonia solution and $20 \%$ methanol in water $(2: 98, \mathrm{v} / \mathrm{v})$. Donepezil were then eluted from the dried columns using $0.5 \mathrm{~mL}$ acetic acid in methanol $(2: 98, \mathrm{v} / \mathrm{v})$. Next, $200 \mu \mathrm{L}$ of the eluent was then diluted with $200 \mu \mathrm{L}$ of $0.05 \%$ trifluoroacetic acid before being injected into the UHPLC system. 


\subsection{Method validation}

The developed method was fully validated according to the Guidance for Industry, Bio-analytical Methods Validation, U.S. Department of Health and Human Services, Food and Drug Administration, Center for Drug Evaluation and Research (USFDA CDER, $2018, \mathrm{BP})^{14}$. The method's selectivity was examined using six sources of drug-free plasma, for which the ideal result should not have interfering peaks at the retention times of DP and IS. The sensitivity at the lower limit of quantification (LLOQ) was also examined through dilution of the DP standard in plasma, which was extracted and then quantified at the lowest detectable concentration with signal to noise ratio $(\mathrm{S} / \mathrm{N})$ greater than 5 .

The linearity and calibration curve were represented by the means of a linear regression model, $y=m x+b$, where $y$ was the ratio of peak area of DP to the peak area of IS, and $x$ is the concentration at different levels, here comprising 10, 50, 100, 150, 200 and 250 $\mathrm{ng} / \mathrm{mL}$. All the calibration levels yielded linear relationships with coefficient of determination $\left(r^{2}\right)$ that exceeded 0.995 .

Stability studies for the auto-sampler, benchtop, freeze-thaw, stock solution, and long-term stability aspects were performed using three replicates of QC) samples at the lower (LQC), middle (MQC), and higher (HQC). The stability of each specific condition was calculated by examination the samples amount under the same conditions to that of the freshly prepared samples. The accuracy and precision were acceptable when within $\pm 15 \%$, while the extraction efficiency should be more than $80 \%$ and the coeffocoent of variance $(\% \mathrm{CV})$ must be within $\pm 15 \%$.

\section{RESULTS AND DISSCUSION}

\subsection{Method development}

The mobile phase compositions were optimized using a mixture of the standard solution of DP and IS. The isocratic program was optimized with the initial ratio of acetonitrile and $0.05 \%$ TFA in milli-Q water varying in the range of $30-50 \%$. The aim was to determine the constituents and separate the co-eluting peaks. The isocratic condition could achieve the seperation with acetonitrile and $0.05 \%$ TFA in milli-Q water at a ratio of 30:70, v/v, but this method has a long analytic time with peak tailing. Therefore, to get the most suitable results, the gradients of mobile phase were optimized. It was found that by performing the separation via 32:68, $\mathrm{v} / \mathrm{v}$ at $0 \mathrm{~min}, 35: 65, \mathrm{v} / \mathrm{v}$ at $1-2.5 \mathrm{~min}$ and $32: 68, \mathrm{v} / \mathrm{v}$ at 3 min, DP and IS can be separated as well. The retention factor $\left(\mathrm{k}^{\prime}\right)$ was 1.83 for DP and 2.51 for IS, while the resolution factor was 4.69. Although, the retention factor was lower than 2, this method demonstrated an excellent separation of DP from the void peak, as shown in Figure 2. The ACQUITY UPLC ${ }^{\circledR}$ Photodiode Array (PDA) Detector from Waters Co. Ltd. (USA) was used at wavelengths between $200-380 \mathrm{~nm}$. The PDA spectra in Figure 2 shown that the best possible sensitivities of DP and IS was $229.8 \mathrm{~nm}$ and $220.0 \mathrm{~nm}$, respectively. However, the specific wavelength for this method was chosen at $230 \mathrm{~nm}$. Here, the wavelength selection was

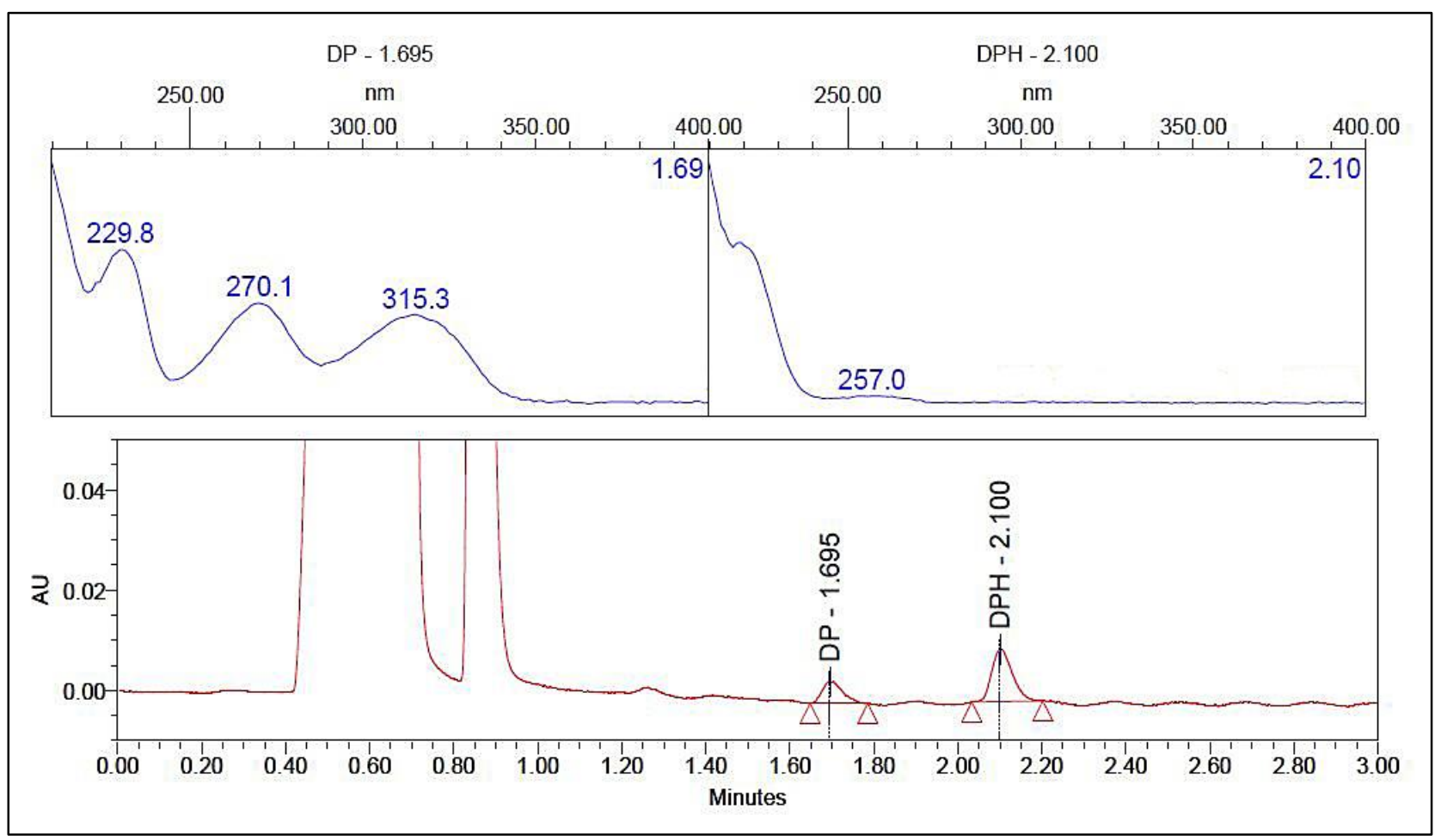

Figure 2. The PDA spectra of donepezil (DP) and diphenhydramine (DPH). 
based totally on the requirement for achieving the highest sensitivity and specificity for DP determination.

\subsection{Method development: sample preparation}

This optimized protocol was able to further removes interferences so a cleaner extract is achieved. A wash-elute study was performed to determine the optimal retention and elution parameter for given drugs on the Oasis sorbent depending on the organic concentration and $\mathrm{pH}$. In reverse phase Oasis ${ }^{\circledR}$ HLB SPE, the retention of a drug is influenced by the organic concentration and $\mathrm{pH}$. Donepezil is a basic drug with a tertiary amine group $(\mathrm{pKa}=8.82)$. Basic drugs will be more retained at a high $\mathrm{pH}$ value (unionized) and less retained at a lower $\mathrm{pH}$ value (ionized). Thus, ammonia solution in water and $10 \%, 20 \%, 30 \%, 40 \%, 50 \%, 60 \%, 70 \%, 80 \%$, $90 \%, 100 \%$ methanol $\mathrm{MeOH}$ in water $(2: 98, \mathrm{v} / \mathrm{v})$ were determined to give the maximum $\% \mathrm{MeOH}$ for the wash solution. Then, acetic acid in water and $10 \%, 20 \%$, $30 \%, 40 \%, 50 \%, 60 \%, 70 \%, 80 \%, 90 \%, 100 \% \mathrm{MeOH}$ in water were determined to give the minimum $\% \mathrm{MeOH}$ for the eluent solution. Finally, ammonia solution in water $(2: 98, \mathrm{v} / \mathrm{v})$ and ammonia solution in $20 \% \mathrm{MeOH}$ in water $(2: 98, \mathrm{v} / \mathrm{v})$ were chosen for the wash solution while acetic acid in in $\mathrm{MeOH}(2: 98, \mathrm{v} / \mathrm{v})$ was chosen for the eluent solution.

\subsection{Assay performance and validation}

\subsubsection{Selectivity and sensitivity}

Six sources of drug-free plasma were studied for assessing the selectivity. There were no interfering peaks at the retention time of DP and IS in selectivity testing. The representative UPLC-PDA chromatogram acquired are presented in Figure 3 for the internal standard sample (A) and the clinical plasma sample (B). The

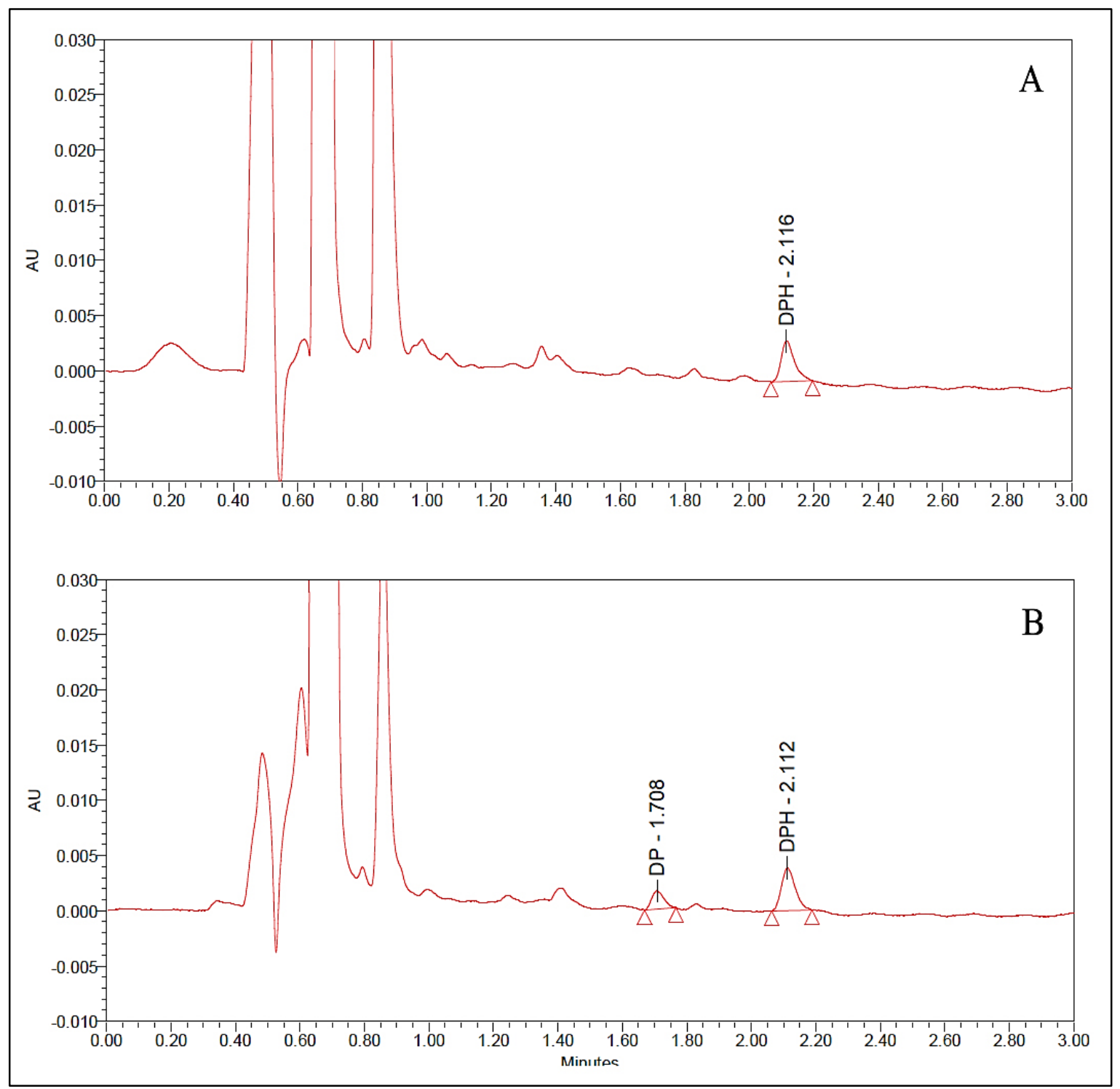

Figure 3. Representative UHPLC-PDA chromatograms obtained from the (A) internal standard sample and (B) clinical plasma sample after an oral administration of $10 \mathrm{mg}$ donepezil. 
lower limit of quantification (LLOQ) was $10.0 \mathrm{ng} / \mathrm{mL}$ with 10.33 signals to noise ratio. Thus, the developed method was shown to be selective and sensitivity for DP and IS.

\subsubsection{Linearity and calibration standard curve}

The six-point calibration standard curve was found to be linear over the concentration range of 10$250 \mathrm{ng} / \mathrm{mL}$. The calibration standard curve was developed by plotting DP to IS peak area ratio (y) towards the DP concentration $(\mathrm{x})$, This method also confirmed to give excellent linearity, with a coefficient of determination $\left(r^{2}\right)$ greater than $0.998(0.9985,0.9983,0.9992$ for three consecutive days) as shown in Figure 4, which was within the acceptance limits and in accordance with the USFDA guidance. The percentage accuracy (or percentage relative error, \%RE) and percentage precision (or percentage coefficient of precision, $\% \mathrm{CV}$ ) were within $\pm 20 \%$ at LLOQ and $\pm 15 \%$ at other concentrations. The results are summarized in Table 1.

\subsubsection{Extraction efficiency}

Assessment of the extraction efficiency of the method was carried out based on 3 replicates analyses of the LQC, MQC, and HQC by evaluating the peak areas of the extracted samples with the peak areas of nonextracted standard solutions at the same concentrations.
The mean absolute recoveries of the LQC, MQC and HQC have been $85.1 \%, 84.6 \%$ and $85.6 \%$, respectively, for DP and $75.0 \%$ for IS. The results indicated that the sample preparation of this method was consistent, precise and reproducible with \% CV equal to 4.18, 3.50, 3.24 and 3.01 for LQC, MQC, HQC and IS, respectively.

\subsubsection{Accuracy and precision}

The within-run and between-run accuracy and precision were examined through the analysis of six replicates of the LLOQ, LQC, MQC, and HQC for three consecutive days. The within-run and between run accuracies of the method were in the range of 91.38 to $106.47 \% \mathrm{RE}$ and 97.99 to $103.03 \% \mathrm{RE}$, respectively. Within-run and between run precision was additionally observed, with \% CV in the range of 1.22 to $3.90 \%$ and 1.59 to $3.69 \%$, respectively. The results are summarized in Table 2. These results indicated that the developed method had sufficient accuracy and precision to determine DP in human plasma.

\subsubsection{Stability study}

Stability of the analysis was assessed by testing three replicates of plasma spiked with three QC concentrations under various conditions and comparing the result with freshly prepared samples. DP was proved to be stable in human plasma under the specified storage

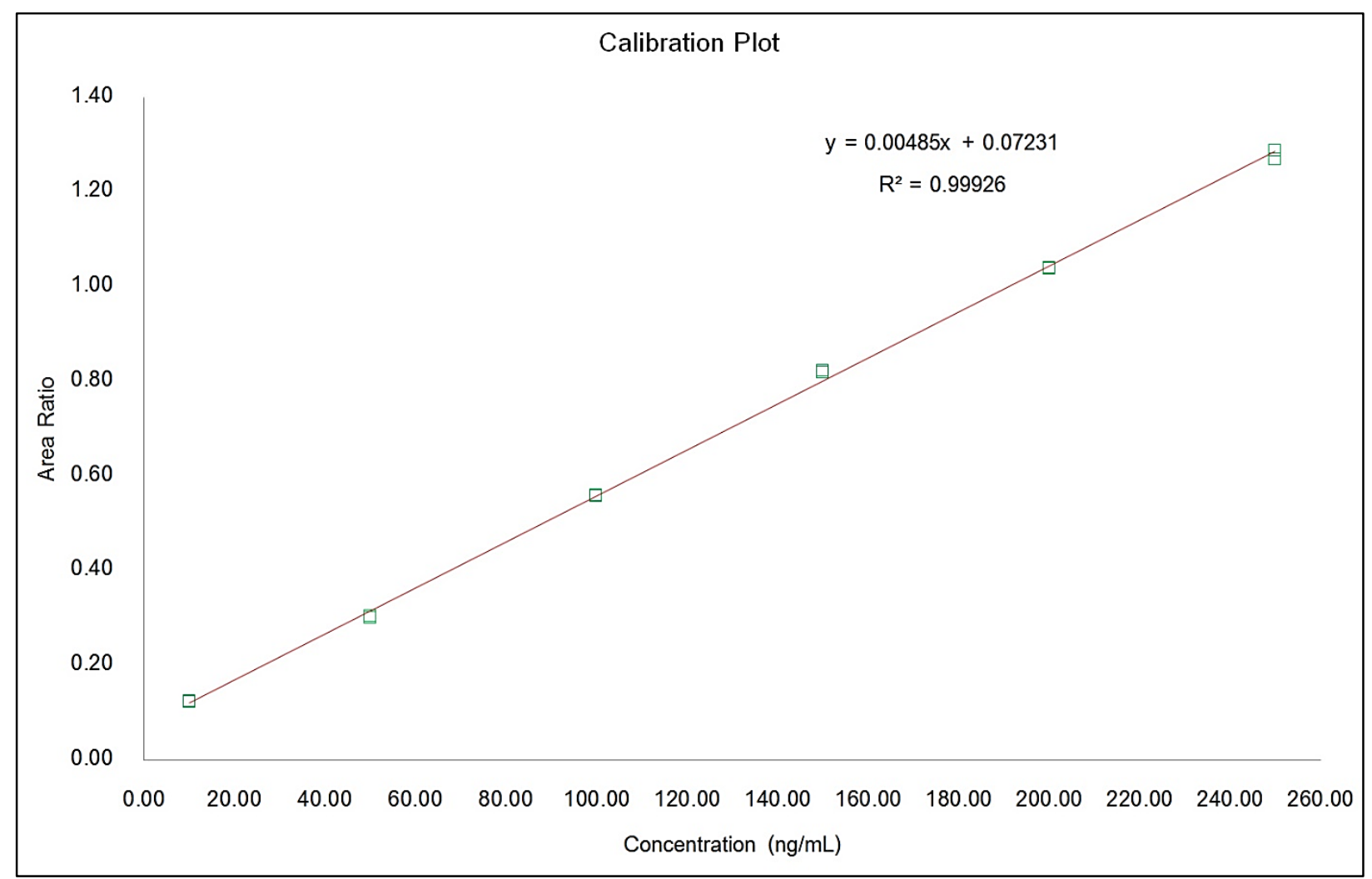

Figure 4. Calibration standard curve of donepezil (day 3) constructed by plotting the peak-area ratios of the donepezil plasma concentration compared to the IS against nominal concentration. 
Table 1. Precision (\%CV) and accuracy (\%RE) of donepezil calibrations standards curve.

\begin{tabular}{cccc}
\hline $\begin{array}{c}\text { Nominal concentration } \\
(\mathbf{n g} / \mathbf{m L})\end{array}$ & $\begin{array}{c}\text { Measured concentration } \\
\text { Mean } \pm \text { SD }(\mathbf{n g} / \mathbf{m L})\end{array}$ & $\begin{array}{c}\text { Precision } \\
(\boldsymbol{\%} \mathbf{C V})\end{array}$ & $\begin{array}{c}\text { Accuracy } \\
(\boldsymbol{\%} \mathbf{R E})\end{array}$ \\
\hline 10.00 & $10.14 \pm 0.79$ & 7.78 & 101.41 \\
50.00 & $49.28 \pm 3.21$ & 6.15 & 98.55 \\
100.00 & $99.16 \pm 4.00$ & 4.03 & 99.16 \\
150.00 & $152.61 \pm 2.67$ & 1.75 & 101.74 \\
200.00 & $199.53 \pm 2.61$ & 1.31 & 99.76 \\
250.00 & $249.29 \pm 3.86$ & 1.55 & 99.72 \\
\hline
\end{tabular}

${ }^{\text {aMean, }} \mathrm{n}=3$ sets of calibration curve

Table 2. Within-run and between-run precision and accuracy study.

\begin{tabular}{|c|c|c|c|c|c|c|}
\hline \multirow{2}{*}{$\begin{array}{l}\text { Nominal concentration } \\
(\mathrm{ng} / \mathrm{mL})\end{array}$} & \multirow[t]{2}{*}{ Day } & \multirow{2}{*}{$\begin{array}{c}\text { Measured value } \\
\text { Mean } \pm \text { SD }(\mathrm{ng} / \mathrm{mL})\end{array}$} & \multicolumn{2}{|c|}{ Accuracy (\%RE) } & \multicolumn{2}{|c|}{ Precision (\%CV) } \\
\hline & & & Within run ${ }^{b}$ & Between runc & Within run ${ }^{b}$ & Between runc \\
\hline \multirow[t]{3}{*}{10.00} & 1 & $10.00 \pm 0.62$ & 100.02 & 99.71 & 6.17 & 4.28 \\
\hline & 2 & $10.06 \pm 0.33$ & 100.58 & 99.71 & 3.32 & 4.28 \\
\hline & 3 & $9.85 \pm 0.31$ & 98.52 & 99.71 & 3.19 & 4.28 \\
\hline \multirow[t]{3}{*}{30.00} & 1 & $29.95 \pm 1.08$ & 99.83 & 100.03 & 3.61 & 2.99 \\
\hline & 2 & $30.07 \pm 0.73$ & 100.24 & 100.03 & 2.41 & 2.99 \\
\hline & 3 & $30.013 \pm 0.96$ & 100.03 & 100.03 & 3.19 & 2.99 \\
\hline \multirow[t]{3}{*}{120.00} & 1 & $117.97 \pm 2.78$ & 98.31 & 97.99 & 2.36 & 3.69 \\
\hline & 2 & $121.08 \pm 1.95$ & 100.90 & 97.99 & 1.61 & 3.69 \\
\hline & 3 & $113.70 \pm 4.43$ & 94.75 & 97.99 & 3.90 & 3.69 \\
\hline \multirow[t]{3}{*}{220.00} & 1 & $224.30 \pm 2.74$ & 101.95 & 101.60 & 1.22 & 1.59 \\
\hline & 2 & $225.445 \pm 2.96$ & 102.48 & 101.60 & 1.31 & 1.59 \\
\hline & 3 & $220.78 \pm 3.51$ & 100.36 & 101.60 & 1.59 & 1.59 \\
\hline
\end{tabular}

${ }^{\mathrm{b}}$ Six replicates $(\mathrm{n}=6)$ at each concentration.

${ }^{c}$ Three day runs $(n=18)$ at each concentration.

Table 3. Stability of donepezil ( $n=3)$.

\begin{tabular}{|c|c|c|c|c|}
\hline Stability & Nominal concentration $(\mathrm{ng} / \mathrm{mL})$ & Precision $(\% \mathrm{CV})$ & Accuracy (\%RE) & $\%$ differences \\
\hline Auto-sampler stability & 30.00 & 1.05 & 101.47 & 2.38 \\
\hline \multirow[t]{2}{*}{ (10 hrs., $8^{\circ} \mathrm{C}, \mathrm{n}=3$ ) } & 120.00 & 1.22 & 99.63 & 2.33 \\
\hline & 220.00 & 0.83 & 101.42 & 1.36 \\
\hline Bench-top stability & 30.00 & 1.33 & 99.42 & 0.31 \\
\hline \multirow[t]{2}{*}{ (4 hrs., $25^{\circ} \mathrm{C}, \mathrm{n}=3$ ) } & 120.00 & 1.13 & 102.69 & 5.48 \\
\hline & 220.00 & 3.63 & 102.81 & 2.75 \\
\hline \multirow{3}{*}{$\begin{array}{l}\text { Freeze and thaw stability } \\
(3 \text { cycles, } n=3 \text { ) }\end{array}$} & 30.00 & 3.47 & 100.17 & 1.07 \\
\hline & 120.00 & 2.74 & 102.08 & 4.85 \\
\hline & 220.00 & 1.49 & 107.36 & 7.29 \\
\hline \multirow{3}{*}{$\begin{array}{l}\text { Long term stability } \\
\left(90 \text { days, }-20^{\circ} \mathrm{C}, \mathrm{n}=3 \text { ) }\right.\end{array}$} & 30.00 & 1.22 & 103.08 & 4.00 \\
\hline & 120.00 & 2.70 & 97.93 & 0.59 \\
\hline & 220.00 & 0.73 & 100.44 & 0.38 \\
\hline
\end{tabular}

$\mathrm{n}=$ number of replicates

conditions regarding the auto-sampler stability $(10 \mathrm{~h}$. in the auto-sampler at $\left.8^{\circ} \mathrm{C}\right)$, bench-top stability $(4 \mathrm{~h}$. at room temperature $25^{\circ} \mathrm{C}$ ), freeze-thaw stability (three cycles) and long-term stability $\left(90\right.$ days at $\left.-20^{\circ} \mathrm{C}\right)$. The percentage differences in the accuracy (\%RE) and precision (\%CV) were within the acceptable range of $\pm 15 \%$. The results are summarized in Table 3 . These results indicated that DP was stable in plasma throughout the sample preparation procedure and under the storage conditions.

\subsubsection{Application}

The method was efficiently used to quantify the steady state donepezil plasma concentration in Thai patients with Alzheimer's disease and vascular dementia. The measured drug concentration of 105 patient's plasma after the administration of donepezil at $10 \mathrm{mg}$ maintenance dose was $36.31-137.31 \mathrm{ng} / \mathrm{mL}^{15}$. The study was approved by the Siriraj Institutional Review Board (539/ 2559(EC1)) of the Faculty of Medicine Siriraj Hospital, Mahidol University, Bangkok, Thailand.

\section{CONCLUSIONS}

An UHPLC-PDA method was developed and proved to be simple, rapid, sensitive and reproducible method for the determination of donepezil concentrations in the patient plasma. It was thoroughly validated 
and found to perform within acceptable limit in accordance with the USFDA standard guideline. Moreover, this method was efficiently utilized to measure the plasma concentration of Thai patients with Alzheimer's disease and vascular dementia.

\section{ACKNOWLEDGEMENT}

This study was carried out under the research framework of Mahidol University and supported by the 90th Anniversary of Chulalongkorn university Fund (GCUGR1125613040D).

\section{Conflict of interest}

The authors declare that they have no conflict of interest.

\section{Funding}

None to declare.

\section{Ethics approval}

This study and was approved by the Siriraj Institutional Review Board (SIRB) No. 539/2559(EC1).

\section{Article info:}

Received January 13, 2021

Received in revised form October 15, 2021

Accepted November 25, 2021

\section{REFERENCES}

1. Cummings JL. Alzheimer's disease. N Engl J Med. 2004;351(1): 56-67.

2. Rogers SL, Doody RS, Mohs RC, Friedhoff LT. Donepezil improves cognition and global function in Alzheimer disease: a 15-week, double-blind, placebo-controlled study. Donepezil Study Group. Arch Intern Med. 1998;158(9):1021-31.

3. Cacabelos R, Torrellas C, Carrera I. Opportunities in pharmacogenomics for the treatment of Alzheimer's disease. Future Neurol. 2015;10(3):229-52.

4. Yang YH, Chen CH, Chou MC, Li CH, Liu CK, Chen SH. Concentration of donepezil to the cognitive response in Alzheimer disease. J Clin Psychopharmacol. 2013;33(3):351-5.

5. Miranda LF, Gomes KB, Tito PA, Silveira JN, Pianetti GA, Byrro RM, et al. Clinical Response to Donepezil in Mild and Moderate Dementia: Relationship to Drug Plasma Concentration and CYP2D6 and APOE Genetic Polymorphisms. J Alzheimers Dis. 2017;55(2):539-49.

6. Khansari MR, Bikloo S, Shahreza S. Determination of donepezil in serum samples using molecularly imprinted polymer nanoparticles followed by high-performance liquid chromatography with ultraviolet detection. J Sep Sci. 2016;39(5):1000-8.

7. Kafkala S, Matthaiou S, Alexaki P, Abatzis M, Bartzeliotis A, Katsiabani M. New gradient high-performance liquid chromatography method for determination of donepezil hydrochloride assay and impurities content in oral pharmaceutical formulation. J Chromatogr A. 2008;1189(1-2):392-7.

8. Yasui-Furukori N, Furuya R, Takahata T, Tateishi T. Determination of donepezil, an acetylcholinesterase inhibitor, in human plasma by high-performance liquid chromatography with ultraviolet absorbance detection. J Chromatogr B Analyt Technol Biomed Life Sci. 2002;768(2):261-5.

9. Matsui K, Oda Y, Nakata H, Yoshimura T. Simultaneous determination of donepezil (aricept) enantiomers in human plasma by liquid chromatography-electrospray tandem mass spectrometry. J Chromatogr B Biomed Sci Appl. 1999;729(1-2):147-55.

10. Lu Y, Wen H, Li W, Chi Y, Zhang Z. Determination of donepezil hydrochloride (E2020) in plasma by liquid chromatography-mass spectrometry and its application to pharmacokinetic studies in healthy, young, Chinese subjects. J Chromatogr Sci. 2004;42(5): 234-7.

11. Xie Z, Liao Q, Xu X, Yao M, Wan J, Liu D. Rapid and sensitive determination of donepezil in human plasma by liquid chromatography/tandem mass spectrometry: application to a pharmacokinetic study. Rapid Commun Mass Spectrom. 2006;20(21):3193-8.

12. Apostolou C, Dotsikas Y, Kousoulos C, Loukas YL. Quantitative determination of donepezil in human plasma by liquid chromatography/tandem mass spectrometry employing an automated liquid-liquid extraction based on 96-well format plates. Application to a bioequivalence study. J Chromatogr B Analyt Technol Biomed Life Sci. 2007;848(2):239-44.

13. Patel BN, Sharma N, Sanyal M, Shrivastav PS. Quantitation of donepezil and its active metabolite 6-O-desmethyl donepezil in human plasma by a selective and sensitive liquid chromatographytandem mass spectrometric method. Anal Chim Acta. 2008;629 (1-2):145-57.

14. U.S. Department of Health and Human Services, Food and Drug Administration. Center for Drug Evaluation and Research (CDER), Center for Veterinary Medicine (CVM). Guidance for Industry Bioanalytical Method Validation. Rockville, Maryland. 2018.

15. Yaowaluk T, Senanarong V, Limwongse C, Boonprasert R, Kijsanayotin P. Influence of CYP2D6, CYP3A5, ABCB1, APOE polymorphisms and nongenetic factors on donepezil treatment in patients with Alzheimer's disease and vascular dementia. Pharmgenomics Pers Med. 2019;12:209-24. 